\title{
Performance of Thermoelectric Module as a Water Cooler and Water Heater
}

\author{
Mohamad Asmidzam Ahamat ${ }^{\# 1}$, Razali Abidin*, Siti Muzahidah Abdullah ${ }^{\# 2}$ \\ " HVACR Section, Universiti Kuala Lumpur, Malaysia France Institute, Bandar Baru Bangi,Selangor, Malaysia. \\ E-mail: ${ }^{1}$ asmidzam@unikl.edu.my, ${ }^{2}$ muzahidah@unikl.edu.my
}

*Department of Mechanical Engineering, Universiti Pertahanan Nasional Malaysia, 57000, Kuala Lumpur, Malaysia

E-mail:razaliabidin@upnm.edu.my

\begin{abstract}
This paper presents the total Coefficient of Performance (CoP) of a thermoelectric module in combined heating and cooling modes, obtained through experiments and thermodynamics mathematical model. Thermoelectric module is a solid state heat pump which has a capability to pump heat with the capacity of $100 \mathrm{~W}$ or lower. One of the module surface will acts as a heat sink while another surface of the module rejects heat. This provides an opportunity to utilize both surfaces for cooling and heating applications. The objective of this work was to determine the total CoP of the thermoelectric module when it was operated in a combination of heating and cooling modes. The total CoP was inferred by fitting the temperature of cold and hot water streams which were obtained from experiments to a mathematical model of the thermoelectric heating and cooling system. The highest temperature difference between hot and cold streams was 40 Kelvin. The worst root-mean-square error between the measured and calculated temperature was 2 Kelvin, except for the hot stream temperature curve in the Condition 1(RMS error was 3.5 Kelvin). It was proved that the total CoP of 4.5 was achievable for thermoelectric module operated in the combined heating and cooling modes. However, the total CoP decreased as the temperature difference between hot and cold streams was increased. It can be concluded that the use of thermoelectric module in heating and cooling modes can improve its CoP which contribute to saving in electrical consumption by the module.
\end{abstract}

Keywords - Thermoelectric module; Coefficient of Performance; heating; cooling.

\section{INTRODUCTION}

This paper presents an application of a thermoelectric module as a solid state heat pump between two streams of water. The cold stream of water acts as a heat sink while the hot stream of water acts as a heat source. By utilizing the heat from the hot stream to a cold stream, the total Coefficient of Performance (CoP) that is greater than unity could be achieved. Arguably, heat can be transferred from the hot stream to the cold stream without using a thermoelectric module but the heat transfer rate could be very low if the temperature difference between the hot and cold streams is very small. Furthermore, the lowest temperature that could be achieved by the hot stream is equal to the temperature of the cold stream, provided a massive heat exchanger is used. Thermoelectric modules offer an opportunity in achieving high heat transfer rate an enable the hot stream to be cooled to the lower temperature relative to the temperature of cold stream.

Thermoelectric modules are widely used in various applications including electronic cooling devices, refrigerators, air-conditioners, power generations, thermal energy sensor and aerospace applications [1]. Thermoelectric module can be used a temperature controller and heat flux meter once calibrated [2]. This developed method is applicable to the calorimetric adsorption of water onto silica gel [3]. Recent publication shows that thermoelectric module also able to measure the rate of desorption of water from silica gel [4]. A combination of nanofluid and thermoelectric module improves the performance of mini channel heat exchanger [5]. These examples show that thermoelectric module can be used in various applications.

In electronic cooling applications, thermoelectric modules were tested in high heat flux cooling applications [6] and it is possible to integrate the module with heat pipe [7] or with conventional water cooling device for performance enhancement [8]. However, all of these applications only concern the cooling effect, and the heat is dissipated to ambient air.

In refrigeration and air conditioning applications, thermoelectric refrigerator can reduce the temperature of a 
cold chamber from $27{ }^{\circ} \mathrm{C}$ to $5{ }^{\circ} \mathrm{C}$ in 44 minutes [9], the measured temperature is the air temperature inside the chamber, not the temperature of the item that undergoes cooling. Integration of thermoelectric with soldier combat clothing could enhance soldier performance due to a more comfortable condition (i.e the temperature) [10]. Increase in the mass of combat clothing may reduce the mobility of soldiers. Furthermore, supply of electricity is very scarce at the combat field. At the moment, application of thermoelectric module air conditioning system is very expensive [11]. However, for cooling of small enclosure where a high reliability is required such as in submarine, thermoelectric module has high potential [12]. The drawback of thermoelectric cooling is its Coefficient of Performance is between 0.3 and 0.7 [13], the CoP could be higher than 1 if the temperature of hot body is higher than the temperature of cold body. To date, there is no report in literature on application of thermoelectric as a combined heater and cooler. This provides an opportunity to improve the Coefficient of Performance and enable complete utilization of energy supplied into the thermoelectric module. Furthermore, there is no energy wasted to surrounding

In this paper, the temperature of hot and cold stream was determined through experiment. Two Conditions were tested which are (1) heating and cooling from the same initial temperatures and (2) cooling of hot stream and heating of cold stream, with different initial temperature. Then, the total Coefficient of Performance of a thermoelectric module in combined heating and cooling mode was inferred by fitting the temperature curves to a mathematical model of the system. The comparisons between the measured and inferred temperatures for both conditions are presented.

\section{EXPERIMENTAL APPARATUS AND PROCEDURES}

This section presents the experimental set-up and the procedures to obtain the data.

\section{A. Experimental apparatus}

The apparatus (Fig. 1) mainly consists three main parts which are (1) a thermoelectric module heat pump, (2) water circulation and (3) data logging systems.

The thermoelectric module (Model: TEC1-12706) was placed between two heat sinks and clamped together to ensure a good contact between the module and heat sink. A thin layer of thermal grease (Electrolube HTCP) with the thermal conductivity of $0.9 \mathrm{~W} / \mathrm{mK}$ was applied at the interface between the module and heat sinks. A DC power supply (Model: Instek GPS-1830D) with the precision of $0.01 \mathrm{~V}$ was used to supply voltage and current into the thermoelectric module.

The water circulation system consists two sets of pump and reservoir. The measured mass flow rate of water was $0.25 \mathrm{l} / \mathrm{s}$. The masses of water in the hot and cold streams water tank were $0.6 \mathrm{~kg}$.

Type $\mathrm{K}$ thermocouples was placed at the inlet and outlet of both hot and cold streams, as indicated in Fig. 1. A TC-08 thermocouple logger was used to record the temperatures. The sampling rate was one Hertz. The current and voltage supplied to the module was recorded manually.

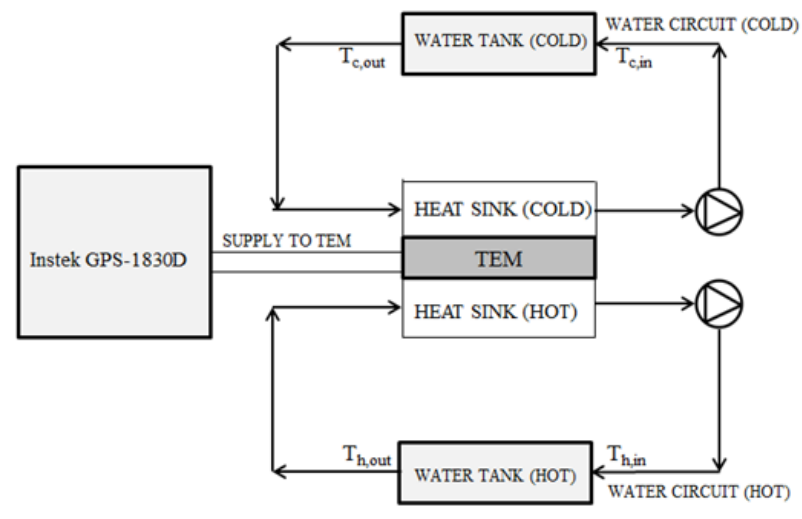

Fig. 1 Apparatus to determine the total $\mathrm{CoP}$ of a thermoelectric module (TEM)

\section{B. Experimental procedures}

This section presents the two types of thermoelectric heat pump conditions that were tested. In both conditions, the voltage supplied to the thermoelectric module was $10.00 \pm$ $0.01 \mathrm{~V}$ throughout the experiment. The magnitude of electrical current was recorded manually.

In the Condition 1, the initial temperatures of hot and cold streams were at $303 \mathrm{~K}$. Then, the TC-08 data logger and DC power supply was turn on simultaneously.

In the Condition 2, the hot stream was heated to $345 \mathrm{~K}$ while the cold stream was cooled to $305 \mathrm{~K}$. These temperatures were used as the initial temperature. Then, the power supply and the data logger were turned on simultaneously.

In both Conditions, the experiment was stopped at the time $=3500$ seconds.

\section{THERMODYNAMICS MODEL OF THERMOELECTRIC COOLER AND HEATER}

A thermodynamics model of thermoelectric module heat pump as in Fig. 1 was developed. Then, the total Coefficient of Performance was inferred.

\section{A. Mathematical model of a thermoelectric heat pump}

Thermoelectric module is a solid state heat pump that works based on the Peltier effect, ohmic heating and conduction between its surfaces (Items 1 to 3 on the right hand side of Equations 1 and 2). The heat pumped on the hot surface $\left(\mathrm{Q}_{\mathrm{h}}\right)$ of the module is presented by Equation 1 while the heat flows through the cold $\left(Q_{c}\right)$ surface is presented by Equation 2,

$$
\begin{gathered}
q_{\mathrm{h}}=S T_{\mathrm{h}} I+0.5 R_{\mathrm{m}} I^{2}+K_{\mathrm{m}} D T \\
Q_{c}=S T_{c} I-0.5 R_{m} I^{2}+K_{m} D T
\end{gathered}
$$

where $\mathrm{S}$ is the Seebeck coefficient, I is the electrical current flowing through the module, $\mathrm{R}_{\mathrm{m}}$ is the module electrical resistance, $K_{m}$ is the module thermal conductance and DT is the temperature difference between the module surfaces.

The Coefficient of Performance of the module in heating $\left(\mathrm{CoP}_{h}\right)$ and cooling $\left(\mathrm{CoP}_{\mathrm{c}}\right)$ modes is presented in Equations 3 and 4 respectively: 


$$
\begin{aligned}
& C o P_{h}=\frac{Q_{b}}{W h} \\
& C o P_{g}=\frac{Q_{g}}{V T}
\end{aligned}
$$

where V and I are the supplied voltage and electric current to the module, respectively.

The total Coefficient of Performance can be calculated using Equation 5:

$$
\operatorname{CoP}_{t}=\operatorname{CoP}_{h}+\operatorname{CoP}_{t}
$$

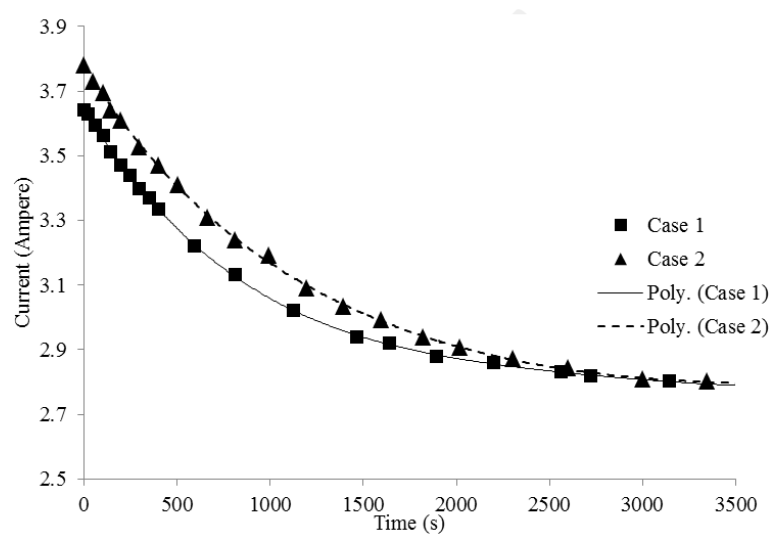

Fig. 2 Electric current flowing through the module, measured (marker) and curve fitted (line)

\section{B. Simulation procedures}

The procedures presented in this section are to enable the determination of the total Coefficient of Performance and average RMS error between the measured and simulated water temperature. The simulation procedures are as below:

1) The first measured temperatures were taken as the initial temperature $(\mathrm{t}=0$ second $)$ in the simulation.

2) Average temperatures of hot and cold surfaces of the module were estimated by taking the temperature of water streams. The stream temperature was obtained by taking the average of inlet and outlet temperature of the tank, as in Fig. 1. The electric current from the experiment were used as the input for Equations 1 and 2. Since the current was measured manually, a curve fitting $\left(\mathrm{R}^{2}>0.999\right)$ was used to obtain the estimated value at every second (Fig. 2). The properties of modules were calculated from the manufacturer datasheet [13].

3) The heat flows on both surfaces were inferred using Equations 1 and 2.

4) The increased/decreased in the streams temperature were determined by Equation 6

$$
\Delta T=\frac{Q}{m c_{p}}
$$

where $\Delta \mathrm{T}$ is the temperature increased/decreased, $\mathrm{Q}$ is $\mathrm{Q}_{\mathrm{h}}$ for hot stream or $\mathrm{Q}_{\mathrm{c}}$ for cold stream, $\mathrm{m}$ is the mass of water in the system and $c_{p}$ is the specific heat of water. The summation of $\Delta \mathrm{T}$ and initial temperature yields $\mathrm{T}_{\text {Theoretical }}$.
5) Total Coefficient of Performance was calculated using Equation 5.

6) The estimated temperature of the streams was compared to the measured temperature to find the RMS error at time step $=\mathrm{t}$ second (Equation 7).

$$
\operatorname{RMS}(t)=\sqrt{T_{\text {measured }}-T_{\text {Theoretical }}}
$$

$\mathrm{T}_{\text {measured }}$ is the average temperatures of the inlet and outlet of the tank, as indicated in Fig. 1.

7) Steps 2 through 6 were repeated until $t=3500$ second.

\section{RESULTS AND DISCUSSION}

This section presents the data obtained from the experiments and simulation, for Condition 1 and Condition 2.

\section{A. Coefficient of Performance for Condition 1}

Fig. 3(a) shows the measured and simulated temperature curves of the hot and cold streams. For the cold stream, the simulated curve does follow closely the measured temperature curve. However, a large deviation between the measured and simulated temperature curve is apparent for the hot stream. The simulation underestimates the hot stream temperature when the temperature is below $340 \mathrm{~K}$, while overestimates for the temperature that is higher than $340 \mathrm{~K}$.

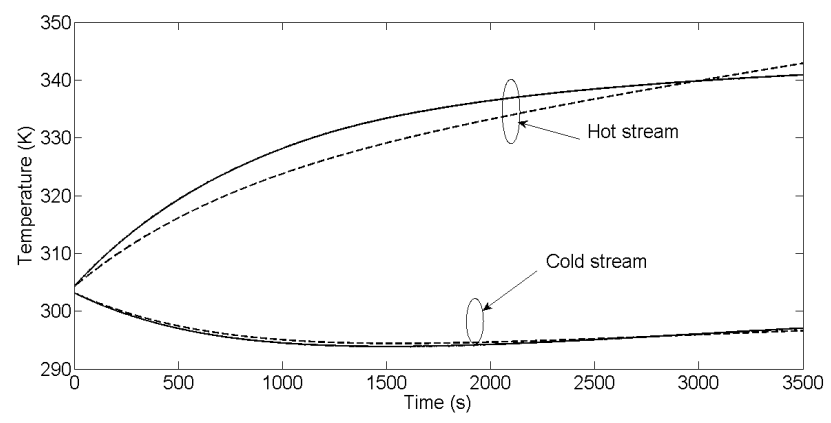

(a)

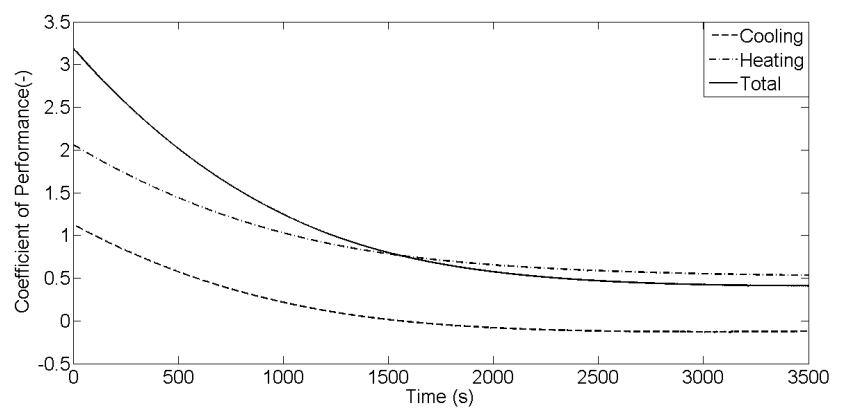

(b)

Fig. 3 Condition 1 (a) temperature curves of measured (solid lines) and simulated (dashed lines) for hot and cold streams (RMS error for cold stream $=0.155 \mathrm{~K}$, RMS error for hot stream $=3.5 \mathrm{~K}$ ), (b) the inferred Coefficient of Performance in heating and cooling modes, and total CoP

The Coefficient of Performance of Condition 1 is presented in Fig. 3 (b). The highest inferred CoP is greater than 3, at the beginning of the experiment. Negative CoP of cooling mode is evidenced when the time is greater than 1500 s. One possible reason is the ohmic heating and 
conduction terms in Equation 2 are higher than the cooling power produced by the Peltier effect of the module.

\section{B. Coefficient of Performance for Condition 2}

In the Condition 2, the simulated temperature curves fairly follow the measured temperature curves for both streams. The total $\mathrm{CoP}$ has the highest value of 4.5 when time is at 1 second. At time $=3500 \mathrm{~s}$, the total $\mathrm{CoP}$ is less than 1. Excessive heat loss to surrounding may leads to the deterioration of $\mathrm{CoP}$.

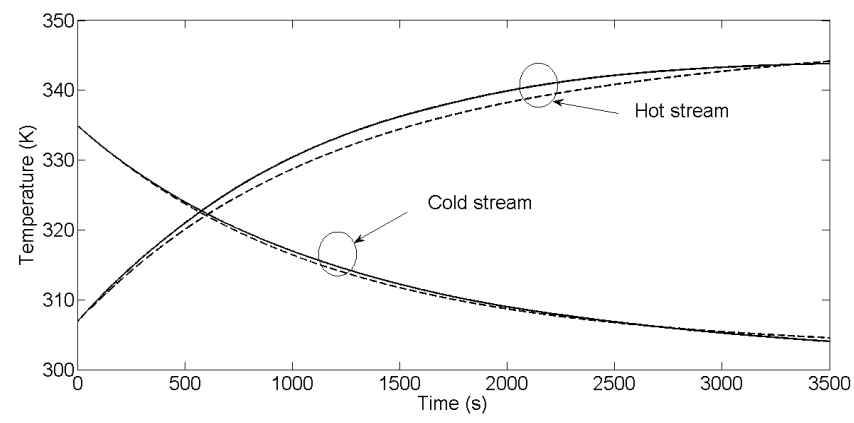

(a)

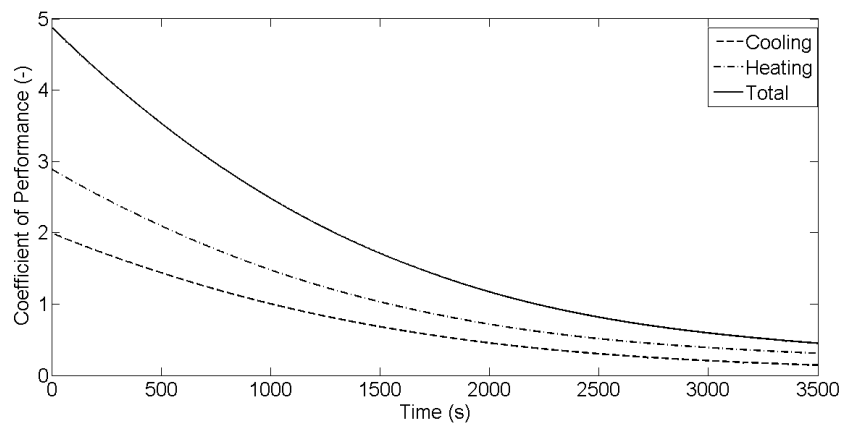

(b)

Fig. 4 Condition 2 (a) temperature curves of measured (solid lines)and simulated (dashed lines) for hot and cold streams (RMS error for cold stream $=0.122 \mathrm{~K}, \mathrm{RMS}$ error for hot stream $=1.762 \mathrm{~K}$ ), (b) the inferred Coefficient of Performance in heating and cooling modes, and total CoP

The performance of thermoelectric module which is operated in the combination of heating and cooling modes significantly increased the CoP by at least $50 \%$, relative to the $\mathrm{CoP}$ when the module is operating in cooling or heating mode alone. This is due to the utilization of heat on both surfaces of thermoelectric module. However, the performance of the module drops significantly due to the increase/decrease in the temperature of its hot/cold side. If the module is operated in cooling mode alone, the hot side temperature can be maintained at an ambient temperature, which helps in maintaining an acceptable CoP.

The rate of heat transfer from the module surfaces to fluid streams is closely related to the heat transfer coefficient between the heat exchange surface and the fluid. Since the module has the heating or cooling capacity that is lower than $100 \mathrm{~W}$, the mass flow rate of the fluid must be kept low to ensure an increase/decrease in stream temperatures at the inlet and outlet can be measured. Although this condition is favourable in achieving higher measurement accurace, this may exacerbate heat transfer performance. Ideally, a higher mass flow rate is desired to increase the heat transfer coefficient between the heat exchange surface and the fluid streams.

In the Condition 1 (Fig.3), it is apparent that the rate of cooling is much lower than the rate of heating. This is due to the nature of thermoelectric module since the ohmic heating is beneficial in heating mode, but it is a disadvantage for cooling mode. If the desired heating and cooling rate should be identical, a bypass of heat flow from the hot surface should be made. This will ensure the excessive heat can be dissipated into environment.

\section{CONCLUSIONS}

A thermoelectric module was used in heating and cooling water streams. The total CoP of 4.5 was achieved in the combined heating and cooling application. However, at higher temperature difference between module surfaces, the total $\mathrm{CoP}$ can be less than 1 , which can be considered as very low. This may happened due to excessive loss of heat to surrounding or the heat conductance between module surfaces dominates the heat flow through the module. This may limit the applications of thermoelectric module, particularly when the temperature difference between module surfaces is very high. Future work may focus on the methods to control the temperature difference between the module surfaces to ensure the total $\mathrm{CoP}$ of thermoelectric module in combined heating and cooling modes are fall within an acceptable range.

\section{NOMENCLATURE}

$\Delta \mathrm{T} \quad$ Increase/decrease in temperature $\mathrm{K}$

$\mathrm{CoP}_{\mathrm{c}} \quad$ Coefficient of Performance in cooling -

$\mathrm{CoP}_{h} \quad$ Coefficient of Performance in heating -

$\mathrm{CoP}_{\mathrm{t}}$ Total Coefficient of Performance -

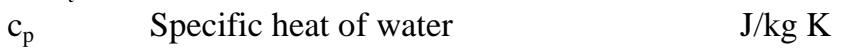

DT Temperature difference K

I Electrical current Ampere

$\mathrm{K}_{\mathrm{c}} \quad$ Thermal conductivity $\quad \mathrm{W} / \mathrm{m} \mathrm{K}$

$\mathrm{m} \quad$ Mass of water in the system $\mathrm{kg}$

Q Heat flow W

$Q_{c} \quad$ Heat flow on the cold surface W

$\mathrm{Q}_{\mathrm{h}} \quad$ Heat flow on the hot surface W

$R_{c} \quad$ Electrical resistance ohm

RMS(t) Root mean square error at time $=\mathrm{t} \quad \mathrm{K}$

$S \quad$ Seebeck coefficient V/K

$\mathrm{T}_{\mathrm{h}} \quad$ Temperature of hot surface $\mathrm{K}$

$\mathrm{T}_{\text {measured }}$ Measured temperature $\mathrm{K}$

$\mathrm{T}_{\text {theoretical }}$ Theoretical temperature $\mathrm{K}$

V Supplied voltage V

\section{ACKNOWLEDGMENT}

Authors would like to acknowledge financial support from Universiti Kuala Lumpur through Short Term Research Grant (str14055) and Final Year Project.

\section{REFERENCES}

[1] Mohamed Hamid Elsheikh, Dhafer Abdulameer Shnawah, Mohd Faizul Mohd Sabri, Suhana Binti Mohd Said, Masjuki Haji Hassan, Mohamed Bashir Ali Bashir, Mahazani Mohamad, A review on thermoelectric renewable energy: Principle parameters that affect 
their performance; Renewable and Sustainable Energy Reviews 30 (2014) 337-355.

[2] M A Ahamat \& M. J. Tierney, Timewise temperature control with heat metering using a thermoelectric module, Applied Thermal Engineering 31 (2011) 1421-1426

[3] M A Ahamat \& M. J. Tierney, Calorimetric assessment of adsorbents bonded to metal surfaces: Application to Type A silica gel bonded to aluminium, Applied Thermal Engineering 40 (2012), 258-266

[4] Mohamad A. Ahamat \& Michael J. Tierney. Calorimetric Assessment of Rates of Desorption, Heat Transfer Engineering, Volume 37, Issue 7-8, 2016

[5] Nizar Ahammed, Lazarus Godson Asirvatham, Somchai Wongwises. Thermoelectric cooling of electronic devices with nanofluid in a multiport minichannel heat exchanger, Experimental Thermal and Fluid Science, Volume 74, June 2016, Pages 81-90

[6] Chein R, Huang G. Thermoelectric cooler application in electronic cooling. Applied Thermal Engineering 2004;24 :2207-17.

[7] Putra N, Yanuar, Iskandar FN. Application of nanofluids to a heat pipe liquid- block and the thermoelectric cooling of electronic equipment. Exp Therm Fluid Sci 2011; 35:1274-81.
[8] Huang H-S, Weng Y-C, Chang Y-W, Chen S-L, Ke M-T. Thermoelectric water- cooling device applied to electronic equipment. Int Commun Heat Mass Transf 2010;37:140-6.

[9] Abdul-Wahab SA, Elkamel A, Al-Damkhi AM, IhA Al-Habsi, AlRubai'ey HS, Al-Battashi AK, et al. Design and experimental investigation of portable solar thermoelectric refrigerator. Renew Energy 2009;34:30-4.

[10] Chen L, Meng F, Sun F. Effect of heat transfer on the performance of thermoelectric generator-driven thermoelectric refrigerator system. Cryo- genics 2012;52:58-65.

[11] Shen L, Xiao F, Chen H, Wang S. Investigation of a novel thermoelectric radiant air-conditioning system. Energy Build 2013;59:123-32.

[12] Riffat SB, Qiu G. Comparative investigation of thermoelectric airconditioners versus vapour compression and absorption airconditioners. Appl Therm Eng 2004;24:1979-93.

[13] www.tetech.com; Assessed in August 2015. 